\title{
Relationship Between Crude Oil Prices And Economic Growth In Selected OPEC Countries
}

Zied Ftiti, EDC Paris Business School, France

Khaled Guesmi, IPAG Business School, France

Frédéric Teulon, IPAG Business School, France

Slim Chouachi, University of Tunis, Tunisia

\begin{abstract}
The aim of this study is to examine the degree of interdependence between oil prices and economic activity growth for four major countries (United Arab Emirates, Kuwait, Saudi Arabia, and Venezuela) in the Organization of the Petroleum Exporting Countries (OPEC) over the period from 3 September 2000 to 3 December 2010. We propose the frequency approach of Priestley and Tong (1973), which is the evolutionary co-spectral analysis. This method offers a time-varying dynamic correlation measure for different horizons, short-run and medium-run. To complete our study by analyzing long-run dependence, we use the cointegration procedure developed by Engle and Granger (1987). We show that oil price shocks in periods during period of fluctuations in the global business cycle and/or financial turmoil affect the relationship between oil and economic growth in OPEC countries.
\end{abstract}

Keywords: Oil Price Shocks; Stock Markets; Evolutionary Co-Spectral Analysis; OPEC; Economic Growth

\section{INTRODUCTION}

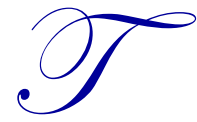

he breakdown of the Bretton Woods regime in 1971 and the occurrence of the primary oil shocks in 1973 have challenged some classical macroeconomic schema, such as the transmission mechanism. Indeed, the abrupt rise in oil prices due the Organization of the Petroleum Exporting Countries (OPEC) oil embargo was followed by a global recession. During this period, some pioneering studies (Rasche and Tatom, 1977, 1981; Darby, 1982; Hamilton, 1983; Burbidge and Harrison, 1984; Santini, 1985; Gisser and Goodwin, 1986) were conducted to examine the relationship between oil price shocks and economic activity to check whether the observed recession (1970s) was attributable to the oil shock of 1973. Hamilton (1983) is the most influential paper in this field; he argued that oil price increases were at least partially responsible for every postsecond world war US recession except the one in 1960. In addition to Hamilton (1983), the above-cited pioneering studies are related to the US economy. These studies have identified a relationship between US economic growth and oil price movement. After these studies, a large number of studies were conducted in various areas. Principally two methodologies were followed. The first methodology in the extant literature evaluates the relationship between oil price shocks and the macroeconomy through theoretical modeling by studying the transmission mechanism channels. Indeed, Hooker (1996) finds that oil prices did not affect many US macroeconomic indicator variables after 1973 (in sense of Granger causality). Rotemberg and Woodford (1996) prove, through using a model involving implicit collusion between oligopolists, that an increase in oil prices leads to a decrease in both output and real wages. However, Bernanke et al. (1997) show that an important part of the effect of oil price shocks on the economy results not from the change in oil prices but from the resulting tightening of monetary policy. More recently, Rogoff (2005) discuss some factors that have weakened the effects of oil shocks, such as higher energy efficiency, deeper financial markets, better anchored monetary policy, greater concentration of oil consumption in final demand and more flexible labor markets. Barsky and Kilian $(2001,2004)$ show that disturbances in the oil market are likely to matter less for US macroeconomic performance than has often been thought. 
The second methodology in the extant literature has focused mainly on the empirical investigation of the relationship between oil price change and national aggregate economic activity. Most of these studies used times series analysis and arrived at mixed results. Lee et al. (1995), by considering both the unanticipated component of real oil price movement and the time-varying conditional variance of oil price change forecasts by using a generalized autoregressive conditional heteroskedastic (GARCH) model, show a negative effect of real oil price changes on industrial production. Papapetrou (2001) arrives at the same results by examining the case of Greece through a VAR model. Miguel et al. (2003) focus on the impact of the oil price change on economic activity in the case of Spain. They used a VAR model and they show a negative impact. Limin et al. (2010) investigate the relationship between the world oil price and China's macroeconomy. By using a VAR model, they show that the world oil price has a non-linear impact to economic activity and inflation of China. Contrary to these findings, Cunado and Perez de Gracia (2003) have analyzed the relationship between oil price and macroeconomy for 15 European countries. Their results show different findings across countries. Indeed, the relationship is identified only in the short-run. for the case of long-run relationship is only identified for the case of United Kingdom and Ireland. In addition, Levin and Loungani (1996) also reported significant differences in gross domestic product (GDP) in response to oil price shocks for G-7 countries.

The oil price crisis observed at the beginning of 1970 due to the OPEC oil embargo was followed by the global recession. Consequently, many studies (Rasche and Tatom, 1977, 1981; Darby, 1982; Hamilton, 1983; Burbidge and Harrison, 1984; Santini, 1985; Gisser and Goodwin, 1986) examined if the recessions were attributable to the oil price shocks. However, these studies indicated a negative correlation between oil prices and real output. Most studies examining the relationship between oil price movements and economic growth are concerned with the US economy. These studies have identified a weak relationship between US economic growth and oil price movement.

Between 1999 and 2008, another episode of oil prices rising have been experienced. These episode was be accompanied by some period of turmoil. Therefore, many studies must be conducted to further understand the effects of oil price movements. These studies must extend the literature in order to give some insights for policy markers and investors. Further, the related literature presented related to the relationship between oil and economic activity is more interested to the case of US. Therefore, this present study considered as an urgent need to close this gap in order to explore this relationship for the case of OECD countries.

Few studies have focused on the relationship between energy and economic growth in relation to OPEC countries. Mehrara and Oskoui (2007) have analyzed the sources of economic fluctuations for USA and some oil exporting countries such as Iran, Saudi Arabia, Kuwait, and Indonesia. By using a structural VAR method, authors identified four structural shocks: supply, oil price, real demand, and nominal demand shocks. They show that oil price shocks represent the main source of output fluctuations in Saudi Arabia and Iran, but not in Kuwait and Indonesia. Other studies have analyzed the relationship between energy and economic growth. However, this relationship is viewed through energy consumption rather than oil price movements (Mehrara, 2007; Ozturk et al., 2010; Gudarzi and Sadr Sayed, 2012; Damette and Seghir, 2013; Behmiri and Pires Manso, 2013).

Our study contributes to the existing literature by taking a novel perspective in assessing the interaction between oil prices and economic growth in OPEC countries. In this paper, we employ a time frequency approach: the evolutionary co-spectral analysis. In contrast to conventional time series approaches, our method proposed a representation of a non-stationary series without any risk of misspecification. Further, the evolutionary spectral analysis does not show an "end-point problem". Moreover, the main contribution of this method consists on the decomposition of the studied time series into frequency and time components. This characteristics allows us to have the dynamic correlation measure between the studied series across different time horizons, for instance, short- and medium-term. To complete our study by analyzing long-run dependence, we use the cointegration procedure developed by Engnle and Granger (1987).

The remainder of the article is organized as follows. Section 2 presents the empirical method and data. The results and discussion are presented in section 3 . Section 4 provides some concluding remarks.

\footnotetext{
${ }^{1}$ In the context of evolutionary spectral analysis did not need no future information or trend projection methods.
} 


\section{EMPIRICAL ANALYSIS}

\section{Methodology}

The interaction between oil price and economic activity is measured in this work through a frequency approach. Indeed, we adopt the theory of evolutionary co-spectral analysis defined Priestley and Tong (1973). ${ }^{2}$ These authors have proposed a coherence function in order to measure the interaction between two time series. More specifically, two time series are analyzed for each country: the oil price $X(t)$ and economic growth $Y(t)$. Each component $(X(t)$ and/or $Y(t))$ is an oscillatory process. Each component is written as follows:

$$
\begin{gathered}
X(t)=\int_{-\pi}^{\pi} A_{\mathrm{t}, \mathrm{x}}\left(w_{1}\right) e^{i w t} d Z_{X}\left(w_{1}\right) \\
Y(t)=\int_{-\pi}^{\pi} A_{\mathrm{t}, \mathrm{Y}}\left(w_{2}\right) e^{i w t} d Z_{Y}\left(w_{2}\right)
\end{gathered}
$$

Let $F_{x}, F_{y}$ denote, respectively, the families of oscillatory functions, $\left\{\varphi_{t, x}\left(w_{1}\right) \equiv A_{t, x}\left(w_{1}\right) e^{i w t}\right\}$, Priestley and Tong (1973) define the evolutionary power cross-spectrum at time $t$ with respect to the families $F_{x}, F_{y}, d H_{t, x y}$ by:

$$
d H_{t, X Y}(w)=A_{t, X}(w) A_{t, Y}^{*}(w) d \mu_{X Y}(w)
$$

If the measure $\mu_{x y}(w)$ is absolutely continuous with respect to the Lebesgue measure, we write for each $t$ :

$$
H_{t, X Y}(w)=h_{t, X Y}(w) d w
$$

where $h_{t, X Y}(w) d w$ is then termed the evolutionary cross-spectral density function.

Based on Priestley (1966) two filters are used to estimate the evolutionary cross-spectral density function. Numerous works have tested the robustness of such filters, such as Ahamada and Boutahar (2002). For the discrete bivariate process, Priestley and Tong (1973) adopt the same option:

$$
g(u)=\left\{\begin{array}{ll}
\frac{1}{2 \sqrt{h \pi}} & \text { if }|u| \leqslant h \\
0 & \text { if }|u|>h
\end{array} \quad W_{v}= \begin{cases}\frac{1}{T^{\prime}} & \text { if }|v| \leqslant \frac{T^{\prime}}{2} \\
0 & \text { if }|v|>\frac{T^{\prime}}{2}\end{cases}\right.
$$

The estimation of the evolutionary cross-spectral density function is as follows:

$$
\hat{h}_{t, X Y}=\sum_{v \in Z} W_{T}^{\prime}(v) U_{x}(w, t-v) U_{Y}(w, t-v)
$$

with

$$
\begin{aligned}
& U_{x}(w, t)=\sum_{u \in Z} g(u) X(t-u) e^{i w(t-u)} d u \\
& Y(w, t)=\sum_{u \in Z} g(u) Y(t-u) e^{i w(t-u)} d u
\end{aligned}
$$

According to Priestley and Tong (1973), the evolutionary cross-spectral density function may be written as:

$$
\begin{aligned}
& h_{t, X Y}(w)=C_{t, X Y}-i Q_{t, X Y}(w) \\
& C_{t, X Y}=\mathcal{R}\left\{h_{X Y}\left(w_{j}, t\right)\right\} \\
& Q_{t, X Y}=\operatorname{Im}\left\{h_{X Y}\left(w_{j}, t\right)\right\}
\end{aligned}
$$

\footnotetext{
${ }^{2}$ For more details on the evolutionary co-spectral analysis estimation, see Ftiti (2010).
} 
where the real-valued functions $C_{t, X Y}$ and $Q_{t, X Y}$ are termed the evolutionary co-spectrum and the evolutionary quadrature spectrum, respectively. If the measures $\mu_{x x}(w)$ and $\mu_{y y}(w)$ are absolutely continuous, Priestley and Tong (1973) similarly define the evolutionary auto-spectral density functions, $h_{x x}\left(w_{j}, t\right), h_{y y}\left(w_{j}, t\right) .{ }^{3}$ The coherency function is defined by the following expression:

$$
C_{t, X Y}=\frac{\left|h_{t, X Y}(w)\right|}{\left\{h_{t, X X}(w) h_{t, Y Y}(w)\right\}^{\frac{1}{2}}}=\frac{\left|E\left[d Z_{Y}(w) d Z_{y}^{*}\right]\right|}{\left\{E\left[d Z_{X}(w)\right]^{2} E\left|d Z_{Y}(w)\right|^{2}\right\}^{\frac{1}{2}}}
$$

Priestley and Tong (1973) interpret $C_{t, X Y}(w)$ as the modulus of the correlation coefficient between $d Z_{x}(w), d Z_{Y}(w)$. $C_{t, X Y}(w)$ is considered as a measure of the linear relationship between corresponding components at frequency $\mathrm{w}$ in the processes $\{Y(t)\}$ and $\{X(t)\}$.

The estimation of the coherency function is written as:

$$
\hat{C}_{t, X Y}(w)=\frac{\left|\widehat{h}_{t, X Y}\right|}{\left\{\widehat{h}_{t, X X} \widehat{h}_{t, Y Y}\right\}^{1 / 2}}
$$

In this paper, we set $h=7$ and $T^{\prime}=7$. These choices ${ }^{4}$ are in line with Artis et al. (1992), Priestley (1996), Ahamada and Boutahar (2002), Essaadi and Boutahar (2010), Bouchouicha and Ftiti (2012), and Ftiti and Hichri (2014).

According to Priestley (1988), we have $E\left(\widehat{h_{t}}(w)\right) \approx h_{t}(w), \operatorname{var}\left(\widehat{h_{t}}(w)\right)$, decreases when $T^{\prime}$ increases. $\forall\left(t_{1}, t_{2}\right)$, $\forall\left(w_{1}, w_{2}\right)$, if at least one of the following conditions (i) and (ii) is satisfied.

$$
\text { (i) }\left|t_{1}-t_{2}\right| \geq T^{\prime} \quad \text { (ii) }\left|w_{1} \pm w_{2}\right| \geq \frac{\pi}{h}
$$

To satisfy conditions $(i)$ and (ii), we choose $\left\{t_{i}\right\}$ and $\left\{w_{j}\right\}$ as follows:

$$
\begin{aligned}
& t_{i}=\{18+20 i\}_{i=1}^{I} ; \text { where } I=\left[\frac{T}{20}\right] \text { and } T \text { is the sample size; } \\
& w_{j}=\left\{\frac{\pi}{20}(1+3(j-1)\}_{j=1}^{7}\right.
\end{aligned}
$$

To respect condition (ii), we inspect instability in these frequencies: $\frac{\pi}{20}, \frac{4 \pi}{20}, \frac{7 \pi}{20}, \frac{\pi 10}{20}, \frac{13 \pi}{20}, \frac{16 \pi}{20}, \frac{\pi 19}{20}$.

From the above seven frequencies, we retain only two frequencies presenting respectively the short-term and medium-term. The medium-term interdependence is presented by the frequency $\frac{\pi}{20}$, and the short-term interdependence is defined by the frequency $\frac{4 \pi}{20}$. The shift from the frequency domain to the time domain is done through the following formula: $\frac{2 \pi}{\lambda} \frac{2 \pi}{\lambda}$, where $\lambda$ is the frequency. For example, the frequency $\frac{\pi}{20}$ corresponds to $\frac{2 \pi}{\frac{\pi}{20}} \frac{2 \pi}{\frac{\pi}{20}}$ months, which is equal to 3 years and 1 quarter. The frequency $\frac{2 \pi}{\frac{4 \pi}{20}} \frac{10 \pi}{20}$ corresponds to the 10 month time frame. We note that by using monthly data, our empirical method is unable to determine the long-run dependence. Therefore, in order to complete the analysis by examining the long-run dependence, we use the cointegration procedure developed by Engle and Granger (1987).

\footnotetext{
${ }^{3}$ For more details, see Ftiti (2010).

${ }^{4}$ This choice of values is justified, as they satisfy conditions (i) and (ii).
} 


\section{Data}

We use monthly data for oil prices and Gross Domestic Product (GDP), for Saudi Arabia, United Arab Emirates, Kuwait, and Venezuela. The main criteria to select our sample is is based on the country's rank in the top 10 oil importers and exporters.

The Brent crude oil index is used as it accounts for $65 \%$ of the daily world oil production (IMF, 2010). We use GDP to determine the economic growth rate $\left(Y_{t}\right)$ for the selected countries through the following formula:

$$
Y_{t}=100 * \ln \left(\frac{G D P_{t}}{G D P_{t-1}}\right)
$$

The data range from 3 September 2000 to 3 December 2010 and have been extracted from Federal Reserve Bank of Saint Louis and the DataStream Database. The time horizon depends on data availability and includes the major economic crises and some important political events (monetary and financial crises in the Asian, Latin American, and Middle East regions, Gulf wars, the Russian economic crisis, and the US terrorist attack).

We note that for the estimation method, described above, leads to lost ten observations at the beginning and at the end of our data spam. As a result, the estimated evolutionary co-spectral density functions between oil price and GDP growth start from 3 August 2001 and extend to 3 February 2010.

Figure 1. The price of Brent crude oil, in dollars, from September 2000 to October $2010 .^{5}$

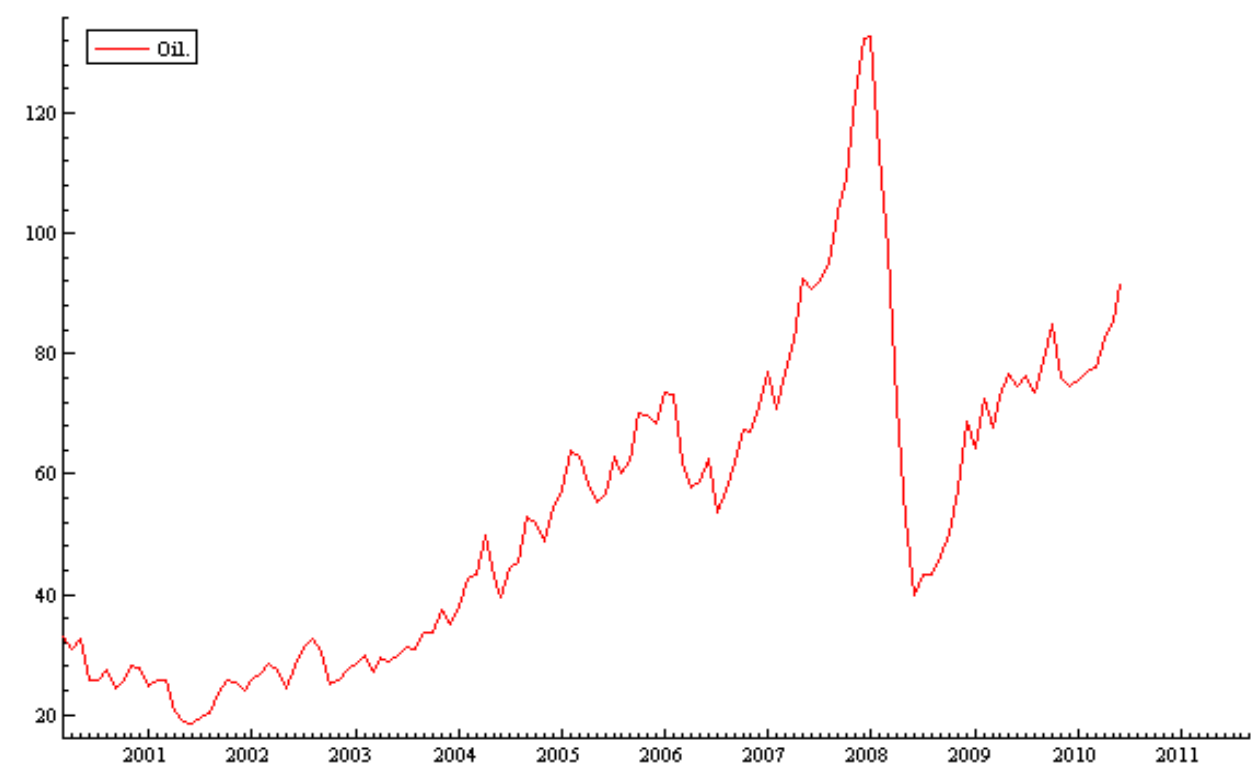

Oil price movements display some important peaks during the period of the study. The main peak is coincided with the period of world financial crisis in 2007 and 2008. Further, in June 2009, another peak is observed when prices increased by more than $60 \%$. We suggest that all these changes are linked to aggregate demand-side oil price shocks. All periods of turmoil have mainly characterized by aggregate demand-side oil price shocks. For example, the first shock occurred during the Asian economic crisis in 1997, and the second took place in 2000, when interest rates decreased significantly, creating a bust in the housing market and construction industries. The third shock took place in the period 2006-2007, as a result of the rising demand for oil from China. Finally, the last chock occurred during the global financial crisis of 2008. These changes are generally explained by major developments and

\footnotetext{
${ }^{5}$ The series appears to exhibit non-stationary behavior, meaning that it does not converge towards its long-term means while the series in the first difference fluctuates around zero and seems to be stationary.
} 
reforms in the oil industry, the significant increase in industrial investment activities dependent on oil-based energy, the impact of oil price regulation policies, and the influence of political events. Tabak and Cajueiro (2007) list many factors (social, economic, and political events), which influence the crude oil price movements.

\section{EMPIRICAL ANALYSIS}

\section{The Time-Varying Coherence Functions}

The analysis resulting from the time-varying coherence functions as computed from equation (4) between each stock market index and the crude oil prices is shown in Figure 2.

Figures 2a to 5b. Coherence functions between the growth rate and the oil price

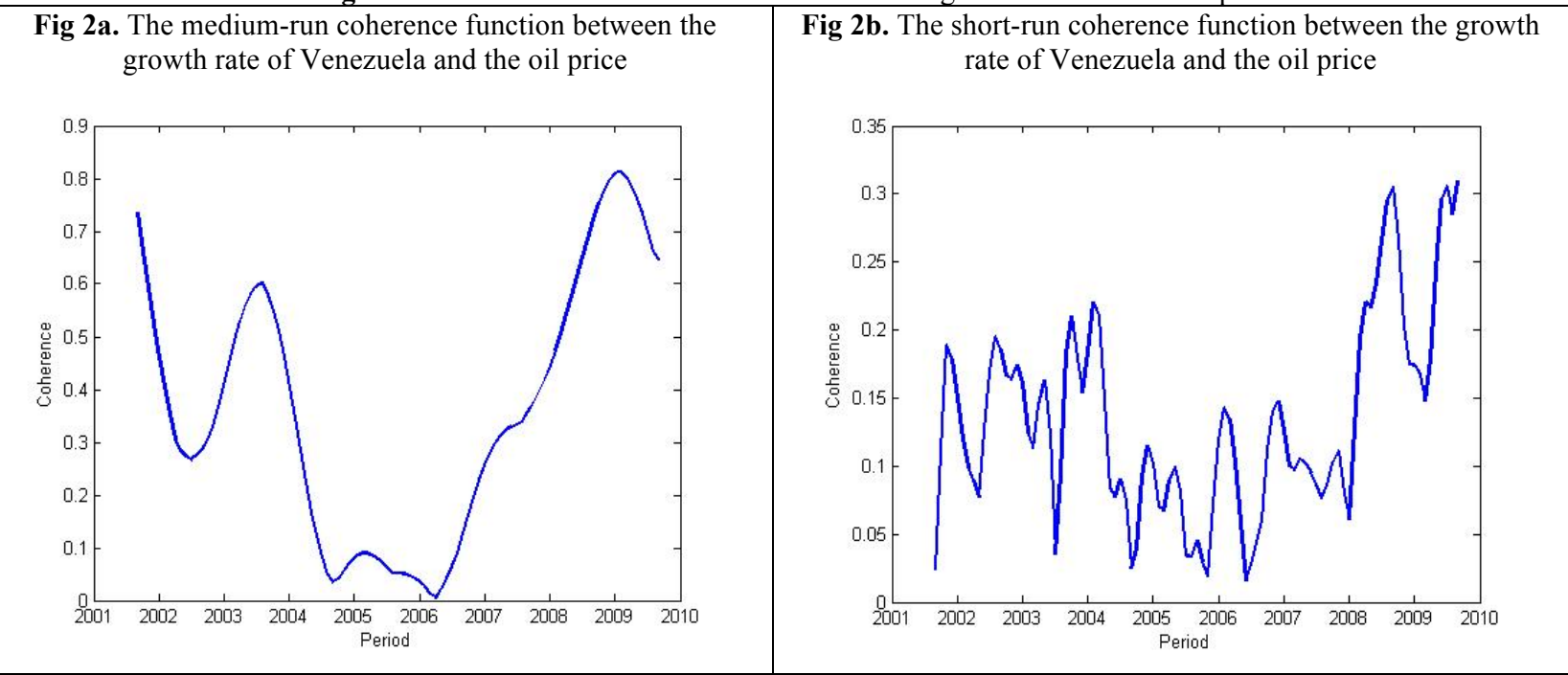

Fig 3a. The medium-run coherence function between the growth rate of Saudi Arabia and the oil price

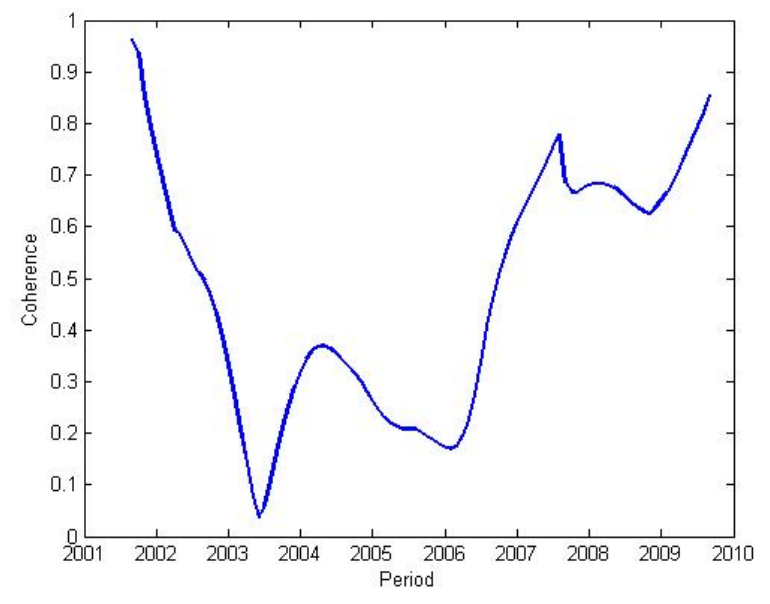

Fig 3b. The short-run coherence function between the growth rate of Saudi Arabia and the oil price

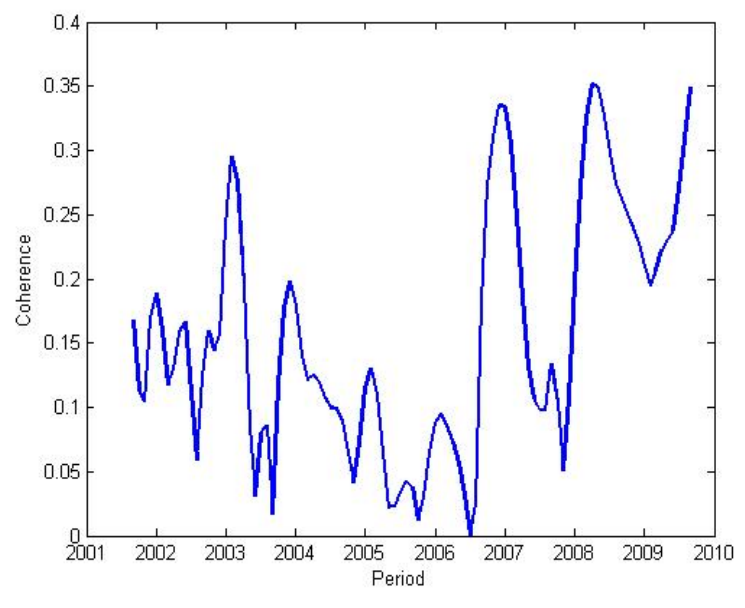


Fig 4a. The medium-run coherence function between the growth rate of the United Arab Emirates and the oil price

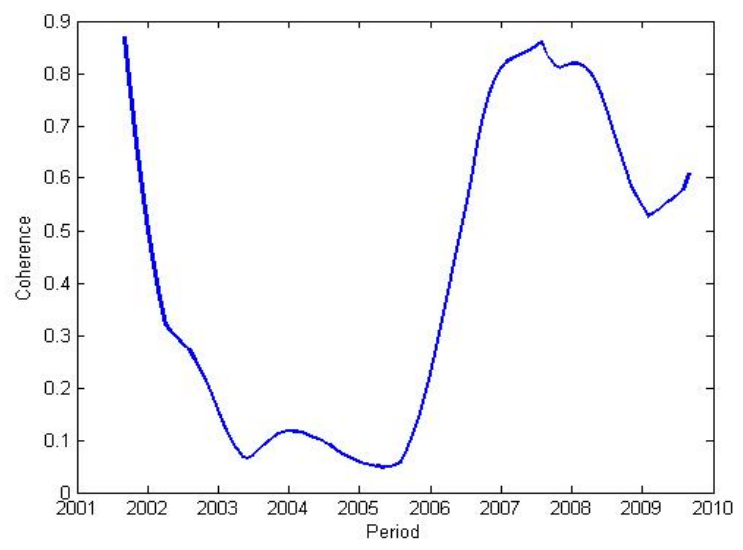

Fig 5a. The medium-run coherence function between the growth rate of Kuwait and the oil price

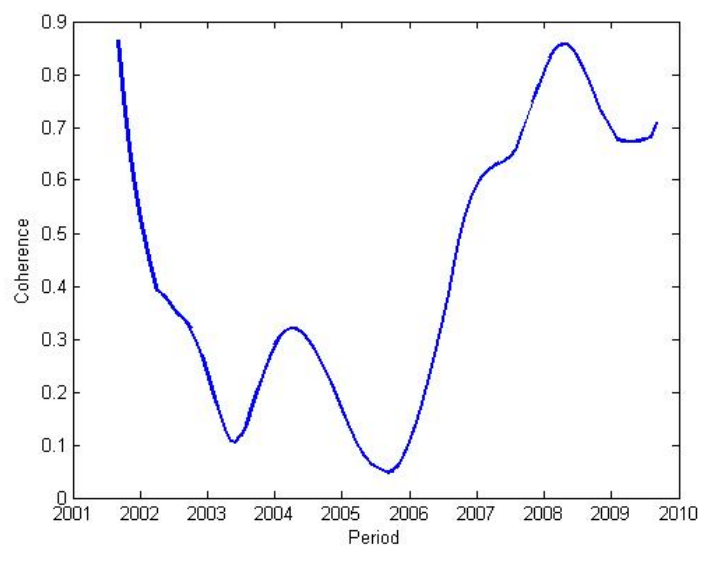

Fig 4b. The short-run coherence function between the growth rate of the United Arab Emirates and the oil price

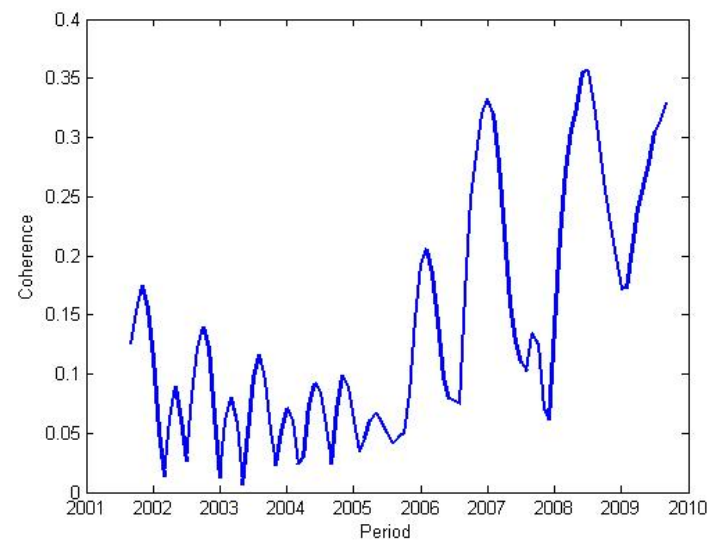

Fig 5b. The short-run coherence function between the growth rate of Kuwait and the oil price

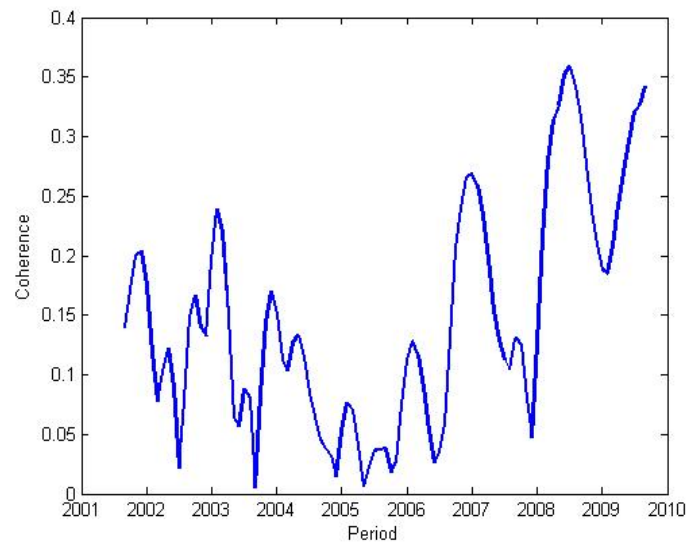

The above graphics show a divergence between the medium-term interdependence of the oil price and economic growth and the short-term one.

In the short-term, the average interdependence does not exceed $20 \%$, while in the medium-term, on average, it reaches more than $60 \%$. Hence, the economic environment reacts weakly to transitory fluctuations of the oil price (short-term interdependence). However, economic activities for all countries react to persistent fluctuations of oil price (medium-term interdependence). These findings are in line with Barsky and Kilian (2001, 2004).

From the graphics $2 \mathrm{~b}$ to $5 \mathrm{~b}$, we observe low interdependences between oil price and real activity in the short-run, particularly in a stable period. These interdependences rise slightly in crisis periods. We show that the interactions between real activity and oil price index are higher in 2001 and 2008 than in other period. In other words, the economic environment reacts slowly to some exogenous shocks (see the appendix, table 1). Our results are in line with previous studies that showing a partial relationship between oil prices movements and economic growth (Hamilton, 1983; Papapetrou, 2001; Miguel et al., 2003; Limin et al., 2010).

Further, graphics $2 \mathrm{a}$ to $5 \mathrm{a}$ show that the dynamic interaction pattern in the medium-term is different from the shortrun one. The OPEC countries face important and multiple peaks in the dynamic coherence patterns, which coincide with very important events (such as the 2008 oil price crisis). We conclude that real activity in OPEC countries 
bears a high interdependence with oil price. This outcome is explained by the fact that the oil sector is the most important economic sector in the case of oil exporting countries, especially the Gulf Cooperation Council (GCC) countries. Our result is contrary to previous studies that show that there is no long-run relationship between oil price and economic growth (Cunado and Perez de Gracia, 2003). We also observe a peak in the medium-term coherence pattern observed around the year 2001 for all countries (80\%). We explain this peak by the housing market and construction industry expansion resulting from the decreasing of worldwide interest rates in 2000.

In 2003, the coherence pattern is smoothed. We suggest that this dynamic of correlation is explained by both important events occurred in this period: the war in Iraq in March 2003 and the PdVSA strike in Venezuela. In 20006, a breakdown in the coherence pattern is observed for all exporting countries. This interaction pattern's is the results of the military attack in Nigeria leading to the shutting down of more than 600,000 billion barrels per day. From the end of 2006 until the end of 2008, we observe a continual increase in the interaction between oil prices and real activity. This period is characterized by an increase of the oil prices, as a result of Chinese demand rising. Therefore, we consider that an aggregate demand-side oil price shock, such as the rising Chinese demand, has a positive impact on the real activity. This result is in line with those Hamilton (2009) and Kilian and Park (2009) that: aggregate demand-side oil price shocks impacts positively the macroeconomic performance.

The explanation for such findings is attributed to the housing market boom in 2000. The expansion of this market leads to favorable world economic environment characterized by an increase of the oil demand. As consequence the price of housing markets have risen exponentially. In similar way, the US terrorist attack in 2011 have created a recession environment as a result of uncertainty rising. The same effect has occurred with chines growth and especially with the last global financial crisis. Based on our results, we suggest that that news about global growth predicts the dynamic of the real oil price. Indeed, during the period, 2003-2008, we have observed a surge in the oil price, which is explained by the rising global demand for industrial commodities driven by unexpected economic growth.

Regarding the transmission channels between business cycles and oil prices, our results provide important explanations pertaining to these transmission mechanisms. Indeed, there are different reasons for an oil shock to affect macroeconomic variables. For example, the non-linear specification of the oil price-macroeconomy relationship could be one such reason. In addition, an increase in the oil price increase reduces aggregate supply, leading to decline of he productivity of a given amount of capital and labor declines, and potential output falls. Consequently to the decline in productivity factor, the real wages decreased. As a result, some labor supply is withdrawn which have a direct impact in decreasing the productivity.

We show that oil price shocks during fluctuations in the global business cycle (downturn or expansion) or financial turmoil exhibit a significant impact on the relationship between oil and real economic activity in OPEC countries. In one hand, the aggregate demand-side oil price shocks (housing market boom, Chinese economic growth, and the global financial crisis) cause a significant higher correlation between real activity and oil prices. In another hand, an important precautionary demand-side oil price shocks (e.g., second war in Iraq, terrorist attacks) tend to cause lower coherence.

\section{Engle and Granger (1987) Results of Cointegration Procedure: Long-Term Dependence}

The results of the cointegration analysis are presented in Appendix (table 2) ${ }^{6}$. We find that the cointegration relationship is identified for all examined countries. Therefore, our results of long run dependence between real activity and oil price are in line with the medium-run hypothesis.

Many factors can explain this result. First, higher oil consumption leads to a stronger negative impact of high oil prices on the national economy, offsetting the positive effects of economic growth. Second, our results are in line with Cunado and Perez de Garcia, saying that "[...] the oil price increase reduces aggregate supply because higher energy prices mean that firms purchase less energy. Consequently, the productivity of any given amount of capital and labor declines, and potential output falls.:The decline in factor productivity implies that real wages will be

\footnotetext{
${ }^{6}$ The code for the cointegration approach is available in MATLAB software.
} 
lower. If some labor supply is withdrawn voluntarily as a result, potential output will be lower than it would otherwise be, thus compounding the direct impact of lower productivity »

Our results suggest that aggregate demand-side oil price shocks (housing market boom, Chinese economic growth, and the latest global financial crisis) cause a significant higher correlation between real activity and oil prices, and important precautionary demand-side oil price shocks (i.e., second war in Iraq, terrorist attacks) tend to cause lower coherence.

\section{CONCLUSION}

This study aims to contribute to the literature on the macroeconomic consequences of oil shocks. First, we complement the existing studies, highlighting the oil-economic growth relationship in the case of OPEC countries. Second, we propose an empirical methodology, "the evolutionary co-spectral analysis," which distinguishes between the short-run dynamic co-movement and the long-run one. Our results show that oil price shocks have both mediumterm and short-term effects on economic growth. However, the impact of the medium-term effects is greater than that of the short-term effects. These results reveal the transmission mechanism channel of the relationship between oil prices and business cycles. First, these transmission mechanisms are active in the short-run and the medium-run. More explicitly, the dependence between oil prices and business cycles can be explained through the impact of oil shocks on aggregate demand (negative impact). Indeed, an increase in oil prices reduces aggregate supply because higher energy prices mean that firms purchase less energy. Consequently, the productivity of a given amount of capital and labor declines, and potential output falls. The decline in factor productivity implies that real wages will be lower.

The major contribution of this study is to distinguish these two types of effects. The medium-term effect is due to the aggregate demand-side oil price shocks (housing market boom, Chinese economic growth, and the latest global financial crisis) that cause a significant higher correlation. In contrast, the short-term effect is caused by important precautionary demand-side oil price shocks (e.g., second war in Iraq, terrorist attacks) that tend to cause lower coherence.

\section{REFERENCES}

Ahamada I., Boutahar M. (2002), Tests for covariance stationarity and white noise, with application to Euro/US Dollar exchange rate. Economics Letters, 77, 177-186.

Artis, M. J., Bladen-Hovell R., and Nachane, D.M. (1992), Instability of Velocity of Money, a New Approach Based on the Evolutionary Spectrum, CEPR Discussion Paper, $\mathrm{n}^{\circ} 735$.

Barsky R., Kilian L. (2001), Do we really know that oil caused the great stagflation ? A monetary alternative, NBER Working Papers 8389.

Barsky R., Kilian L. (2004), Oil and the Macroeconomy Since the 1970s. Journal of Economic Perspectives 18 (4), $115-134$.

Behmiri N., Pires Manso J. (2013), Hox Crude Oil impacts on Economic Growth : An empirical Investigation in Multiple Regions, Working Paper, available at SSRN.

Bernanke B., Gertler M., Watson M. (1997), Systematic Monetary Policy and the Effects of Oil Price Shocks. Brookings Papers on Economic Activity 1, 91-157.

Bouchouicha R., Ftiti Z. (2012), Real estate markets and the macroeconomy: a dynamic coherence framework. Economic Modelling 29, 1820-1829.

Burbidge J., Harrison A. (1984), Testing for the Effects of Oil-Price Rises Using Vector Autoregressions. International Economic Review, vol. 25(2), 459-84.

Cunado J., Perez de Gracia F. (2003), Do oil price shocks matter? Evidence from some European countries, Energy Economics 25, 137-154.

Damette O., Seghir M. (2013), Energy as a Driver of Growth in oil exporting countries ? Energy Economics 37, $193-199$.

Darby M. (1982), The Price of oil and World inflation and Recession. American Economic Review 72 (4), 738-751.

Engle R., Granger W. (1987), Co-Integration and Error Correction: Representation, Estimation, and Testing, Econometrica, vol. 55 (2), 251-276.

Essaadi E., Boutahar M., 2010. A Measure of Variability in Comovment for Economic Varaibles: a Time-Varying Coherence Function Approach, Economics Bulletin vol. 30(2), 1054-1070.

Ftiti Z. (2010), The macroeconomic performance of the inflation targeting policy: An approach based on the evolutionary cospectral analysis (extension for the case of a multivariate process). Economic Modelling 27, 468-476. 
Gisser M., Goodwin T. (1986), Crude Oil and the Macroeconomy: Tests of Some Popular Notions. Journal of Money, Credit, and Banking 18, 95-103.

Gudarzi Y., Sadr Seyed M. (2012), Causality between oil consumption and economic growth in Iran: an ARDL testing approach. Asian Economic and Financial Review 2 (6), 678-686.

Hamilton J. (1983), Oil and the Macroeconomy Since World War II. Journal of Political Economy 91, 228-248.

Hamilton J. (2009). Causes and consequences of the oil shock of 2007-08. Brooking papers on Economic Activity, spring, 215261.

Hooker M.A. (1996), What Happened to the Oil Price-Macroeconomy Relationship? Journal of Monetary Economics 38, 195213.

Kilian L., Park C. (2009), The impact of oil price shocks on the U.S market. International Economic Review 50, $1267-1287$.

Lee, K., Ni, S., Ratti. R. A., 1995. Oil shocks and the Macroeconomy: The role of Price Variability. Energy Journal 16(4), $39-56$.

Limin D., He Y., Chu W., (2010), The relationship between oil price shocks and China's macro-economy: An Empirical analysis. Energy Policy 38 (8), 4142-4151.

Levin A., Loungani P. (1996), Oil, money and economic activity in the G7 countries. Paper presented at the DOE Conference, Washington D.C., october.

Mehrara M. (2007), Energy consumption and Economic Growth: The case of oil exporting countries. Energy Policy 35, $2939-$ 2945.

Mehrara M., Oskoui K. (2007), The source of macroeconomic fluctuations in oil exporting countries: A comparative study. Economic Modelling 24 (3), 365-379.

Miguel C., Manzano B., Martin-Moreno J. (2003), Oil price shocks and aggregate fluctuations, The Energy Journal 24 (2), $47-$ 61.

Ozturk I., Aslan A., Kalyoncu H. (2010), Energy Consumption and Economic Growth relationship evidence from panel data for low and middle income countries. Energy Policy 38, 4422-4428.

Papapetrou E. (2001), Oil prices shocks, stock market, economic activity and employment in Greece, Energy Economics 23, 511532.

Priestley M.B. (1966), Design relations for non stationary processes. Journal of Royal Statistic Society. ser. B, 28, $228-240$.

Priestley M.B., Tong H. (1973), On the analysis of bivariate non-stationary processes. Journal of Royal Statistic Society. ser. B, $35,135-166$.

Rasche R., Tatom J. (1977), The effects of the new energy regime on economic capacity, production, and prices. Review, Federal Reserve Bank of St. Louis, issue may, 2-12.

Rasche R., Tatom J. (1981), Energy price shocks, aggregate supply and monetary policy: the theory and the international evidence. Carnegie-Rochester Conference Series on Public Policy 14 (1), 9-93.

Rogoff K. (2005), Oil and the global economy. International Energy Forum meeting, Riyadh, november 19.

Rotemberg J., Woodford M. (1996), Imperfect Competition and the Effects of Energy Price Increases on Economic Activity.Journal of Money, Credit and Banking28(4), 550-577.

Santini D. (1985), The Energy-Squeeze Model: Energy Price Dynamics in U.S. Business Cycles. International Journal of Energy Systems 5, 18-25.

Tabak, B.M., Cajueiro, D.O., 2007. Are the crude oil markets becoming weakly efficient over time? A test for time-varying longrange dependence in prices and volatility. Energy Economics 29, 28-36. 


\section{APPENDIX}

Table 1. Oil price shock origin and their main events

\begin{tabular}{lcc}
\hline \multicolumn{1}{c}{ Events } & Year & Oil price shock origin \\
\hline Housing market boom & 2000 & Aggregate demand side \\
09/11 Attacks & 2001 & Precautionary demand \\
PdVSA worker's strike & 2002 & Supply side \\
Second war in Iraq & 2003 & Precautionary demand \\
Chinese economic growth & $2006-2007$ & Aggregate demand side \\
Global financial crisis & 2008 & Aggregate demand side \\
Golbal debt crisis & 2010 & Aggregate demand side \\
\hline
\end{tabular}

Sources: Kilian's (2009) and Hamilton (2009) findings.

Table 2. Results of Cointegration analysis.

\begin{tabular}{|c|c|c|c|c|}
\hline$X_{2, t}$ & T-statistics & $\begin{array}{c}\text { Critical value }^{7} \\
(0.05 \%)\end{array}$ & $\begin{array}{c}\text { Critical value } \\
(0.01 \%)\end{array}$ & Conclusion \\
\hline Dubai & & -3.38763 & -3.73 & \\
\hline Kuwait & & -3.38763 & -3.73 & \\
\hline South Africa & & -3.38763 & -3.73 & \\
\hline Venezuela & & -3.38763 & -3.73 & \\
\hline
\end{tabular}

${ }^{7}$ Critical value for MacKinnon for two variables. 


\section{NOTES}

